\title{
Editorial
}

\section{A new leaf}

This will be my last Editorial of the Proceedings in my present capacity, as I handed over the reins to Dr Gail Goldberg at the end of 2000, having spent five enjoyable years reading manuscripts on everything from the molecular biology of leptin to the world food supply. The changes to the journal over that time can be immediately observed by simply looking at it on the shelf; the publisher has changed (from CUP to CABI), in turn leading to changes in size (larger format), finish (shiny, more informative cover) and organisation of the contents (now double-column format). A glance at the 'Directions' indicates how we have embarked on the electronic age, with submission of manuscripts on diskette or as email attachments now possible, together with much more rapid and efficient communication between authors and editors via email than previously; both of these greatly facilitate the handling of manuscripts. Indeed it is likely that soon there will be readers of these papers who will not want the hard copy to put on a shelf, but will opt for the electronic version only; though perhaps for most of us the opportunity to browse through a paper journal is not something we wish to give up. An encouraging level of interest has been shown in the electronic journal; in March 2000 some 250 articles were requested, rising to 337 articles requested in May. This in turn would be expected to enhance the journal's impact factor, so long as the articles are cited!

Similarly, the Original Communications (OC) are becoming more and more 'electronified'; submission and editing are now carried out electronically, access to the OC before the meeting is via the Society's web page, and we are aiming to have electronic return of submission and copyright assignment forms in the near future. All this is intended to speed up the processing of the OC; it should therefore be possible to bring the submission date closer to that of the meeting, so the data presented can be as up to date as possible. Publication can also be quicker, since there should be few OC that are not finalised at the meeting, hence the data could be in the public domain within a few months of being generated. Some authors have perhaps found that their data have been almost too public, due to the free access to the OC on the Society's website; thus any authors who do not wish their OC to be accessible until published in its final form should take note of the tickbox on the OC submission form which offers the option of saying yes or no to the website posting!

Volume 60 of the Proceedings, or course, marks the journal's (and the Nutrition Society's) Diamond Jubilee, and will, appropriately, contain some forward-looking papers. The first three issues will be dominated by the plenary lectures, symposia and OC from the 2000 Summer meeting in Cork, which had the general topic 'Research themes for the new millennium'. The question of population growth and the resources required to provide for all of the people all of the time, even with the input from new technologies, is addressed; while, on a smaller scale, we will have four papers on 'Future perspectives in nutrition and behaviour research'. The future of animal production and how a supply of safe, healthy foods from animals might be achieved is another area of concern to human omnivores; this symposium has the title 'Quality inputs for quality foods'. Molecular aspects of development are considered in the symposium on 'The relative contribution of diet and genotype to development', including a very thoughtprovoking paper on what, exactly, seems to cause osteoporosis in Western populations (and it isn't primarily due to a lack of dietary $\mathrm{Ca}$ !), while the theme of bone is further addressed in the symposium on 'Nutritional aspects of bone metabolism: from molecules to organisms'. Nutritional aspects of cancer, the disease of the future for many of us, are also covered, including energy flux and the role of steroid hormones and growth factors, and physical activity and cancer risk. A related area, 'Nutrition and immunity' is the subject of a group of papers looking at, for example, the merits and demerits of breast milk and cow's milk from the point of view of malnutrition and infectious diseases, on the one hand, and autoimmune disease on the other. There are also three papers on the role of specific micronutrients in immune function, probably of consequence to all of us due to the potential for self-administration of these micronutrients among the population, in addition to their increasingly widespread use by those in clinical practice. The Clinical Nutrition and Metabolism Group have embraced a similar theme for part of their BAPEN symposium on 'Evidence-based nutrition', while the Association for the Study of Obesity, at a joint meeting with the Nutrition Society, will discuss new perspectives on 
adipose tissue function, just in case anyone thought obesity was not going to be an issue in the next millennium!

It is appropriate to close with thanks to the Editorial staff, particularly Christine Hughes, who has been long-term Technical Editor of the manuscripts published in the Proceedings. She tells me it is a satisfying task, for the most part; she certainly performs it immaculately, as the authors will agree! All the others involved with producing this journal (and its sister journals) should also take a bow; it has been great working with you. I am looking forward to seeing the Society's publications progress still further over the next few years, especially, of course, the Proceedings; happy hunting, Gail!

K. M. Younger Editor 